\title{
miR-30a Negatively Regulates TGF- $\beta 1$-Induced Epithelial-Mesenchymal Transition and Peritoneal Fibrosis by Targeting Snai1
}

\author{
Qin Zhou, ${ }^{* \dagger}$ Man Yang, ${ }^{*}$ Huiyao Lan, ${ }^{\ddagger}$ and Xueqing $\mathrm{Yu}^{* \dagger}$
}

From the Department of Nephrology, ${ }^{*}$ The First Affiliated Hospital, Sun Yat-sen University, Guangzhou; the Key Laboratory of Nephrology, ${ }^{\dagger}$ Ministry of Health, Guangzhou; and the Department of Medicine and Therapeutics, ${ }^{\ddagger}$ Li Ka Shing Institute of Health Sciences, The Chinese University of Hong Kong, Hong Kong, China

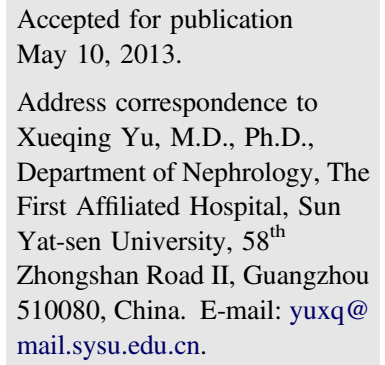

\begin{abstract}
Although epithelial-mesenchymal transition (EMT) and the subsequent development of peritoneal fibrosis are key processes leading to the peritoneal failure related to peritoneal dialysis (PD), mechanisms underlying these processes remain largely unclear. In the present study, we found that miR-30a was significantly down-regulated in peritoneal tissues, with progressive fibrosis in patients with continuous ambulatory peritoneal dialysis and in a rat model of PD. In vitro, transforming growth factor (TGF)- $\beta 1$-induced EMT, identified by de novo expression of $\alpha$-smooth muscle actin and a loss of E-cadherin in both human and rat peritoneal mesothelial cells, was associated with down-regulation of miR-30a but up-regulation of Snai1, suggesting a close link between miR-30a and Snai1 in TGF- $\beta 1-$ induced peritoneal fibrosis. It was further demonstrated in vitro that miR-30a was able to bind the $3^{\prime}$ untranslated region of Snai1 and overexpression of miR-30a blocked TGF- $\beta 1$-induced up-regulation of Snai1 and, therefore, inhibited EMT and collagen expression. To determine the functional role of miR$30 \mathrm{a}$, we overexpressed miR-30a in the peritoneal tissue in a rat model of PD and found that overexpression of miR-30a blocked both Snai1 and EMT and inhibited peritoneal fibrosis, with improvement of peritoneal dysfunction. In conclusion, miR-30a negatively regulates Snai1-mediated EMT during peritoneal fibrosis in vitro and in vivo. Blockade of peritoneal fibrosis by overexpressing miR-30a in a rat model of PD reveals a therapeutic potential of miR-30a for peritoneal fibrosis associated with PD. (Am J Pathol 2013, 183: 808-819; http://dx.doi.org/10.1016/j.ajpath.2013.05.019)
\end{abstract}

Peritoneal fibrosis is a major and severe complication of peritoneal dialysis (PD). Continuous exposure to highglucose PD solution is a cause of progressive peritoneal fibrosis, resulting in a loss of peritoneal membrane function. ${ }^{1}$ It is reported that peritoneal thickness progressively increased as the PD treatment prolonged. ${ }^{2,3}$ Emerging evidence shows that, under high-glucose conditions, transforming growth factor (TGF)- $\beta 1$-induced epithelial-mesenchymal transition (EMT) of peritoneal mesothelial cells may be an important process of peritoneal fibrosis. ${ }^{4}$ Indeed, TGF- $\beta 1$ is a critical cytokine that can induce EMT and production of extracellular matrix in several tissues and organs. ${ }^{5,6}$ TGF- $\beta 1$ binds its receptor on the cell membrane and triggers profound molecular reprogramming, including down-regulation of the intercellular adhesion molecule, E-cadherin (E-cad), and up-regulation of mesenchymal-associated genes, such as Snai1, collagen I (Col I), fibronectin, and $\alpha$-smooth muscle actin ( $\alpha$-SMA). However, mechanisms by which TGF- $\beta 1$ induces EMT and peritoneal fibrosis remain largely undefined.

microRNAs (miRNAs) are small noncoding RNAs and modulate the target gene expression either by promoting mRNA degradation or inhibiting protein translation. ${ }^{7-9}$ Accumulating evidence shows that miRNAs regulate

Supported by Key Program of the National Natural Science Foundation of China grant 81130012, Major State Basic Research Development Program of China grants 2011CB504005 and 2012CB517700, Young Scientists Fund of the National Natural Science Foundation of China grant 81100542, and Hong Kong Research Grants Council grants CUHK5/CRF/ 09 and CUHK3/CRF/12R.

Q.Z. and M.Y. contributed equally to this work. 
diverse biological processes, including cell proliferation, differentiation, and apoptosis, and that aberrant miRNA expression can lead to severe diseases. ${ }^{10,11}$ Recent studies in cancer show that miRNAs, such as the miR-155 or miR-200 family, may modulate the EMT process by mediating or inhibiting downstream of the TGF- $\beta$ signaling pathway. ${ }^{12,13}$ In the context of fibrosis, several miRNAs, such as miR-29, miR-15b, and miR-16, have been identified. ${ }^{14}$ Recently, it was found that miR-589 was decreased in HMrSV5 cells treated with TGF- $\beta 1$ and in human peritoneal mesothelial cells (HPMCs) isolated from effluents of patients with longterm continuous ambulatory peritoneal dialysis (CAPD). ${ }^{15}$ However, it remains unclear whether miRNAs are involved in modulating the EMT process during PD-related peritoneal fibrosis.

Snail is a transcript factor of the Snail family; three members of the Snail family of proteins are known. ${ }^{16}$ Snail overexpression can lead to a dramatic conversion from epithelial cells to a fibroblastic phenotype during cancer progression. ${ }^{17} \mathrm{In}$ the present study, we hypothesized that miR-30a may be lost in response to TGF- $\beta 1$ during peritoneal fibrosis and that overexpression of miR-30a may be able to inhibit peritoneal fibrosis and, therefore, attenuate peritoneal dysfunction in a rat model of PD. By using miRNA microarray and real-time PCR, we identified that loss of miR-30a was associated with peritoneal fibrosis in both an experimental rat model of PD and in patients with CAPD. We also identified that Snail was a target of miR-30a. In a rat model of PD, peritoneal fibrosis was associated with up-regulation of Snail when miR-30a decreased. In contrast, overexpression of miR-30a was capable of suppressing Snai1, thereby inhibiting TGF- $\beta 1$-induced EMT and peritoneal fibrosis in vitro and in vivo.

\section{Materials and Methods}

\section{Animal Model}

Male Sprague-Dawley rats weighing 150 to approximately $200 \mathrm{~g}$ were purchased from the Laboratory Animal Center of Sun Yat-sen University (Guangzhou, China). A rat model of peritoneal fibrosis was induced, as previously described. ${ }^{18}$ Briefly, rats were injected intraperitoneal with $4.25 \%$ dextrose PD solution (Baxter, Deerfield, IL) at $100 \mathrm{~mL} / \mathrm{kg}$ daily for 4 weeks. For microRNA microarray analysis, rats were randomly subgrouped to normal control and PD treatment ( $n=8$ in each group). To determine the optimal expressing pattern and duration of transgene miR-30a in peritoneal tissues mediated by the ultrasound-microbubble gene transfer technique, three rats in each time point $(5,10$, and 15 days) were used. To examine the functional role of miR-30a in PD-induced peritoneal fibrosis, rats were randomly allocated into five groups ( $n=5$ in each group). Rats in group Sa received daily intraperitoneal injections of saline solution ( $0.9 \%$ sodium chloride) for 4 weeks; rats in groups PD, miR-30a, and NC received daily i.p. injections of PD solution with $4.25 \%$ dextrose for 4 weeks, with or without treatment of miR-30a plasmid or NC plasmid at 1, 10, and 20 days; rats in group Con were as the age-matched normal control. After 4week PD treatment, both parietal and visceral peritoneal tissues were collected for analysis, as described later. All animal experiments were approved by the Committee on Animal Experimentation of Sun Yat-sen University and performed in compliance with the university's Guidelines for the Care and Use of Laboratory Animals.

\section{Cell Culture}

A human peritoneal mesothelial cell line, HMrSV5 (HPMCs), was used in this study. ${ }^{19,20}$ The HMrSV5 cell (kindly provided by Dr. Jian Yao, Department of Nephrology, Shanghai First People's Hospital, Shanghai, China) was originally established and well documented by Ronco and coworkers, ${ }^{19}$ as previously described. The cell was characterized as cytokeratin- $18^{+}$and vimentin $^{+}$, as shown in Supplemental Figure S1A. Cells were grown in Dulbecco's modified Eagle's medium/F12 medium containing $10 \%$ fetal bovine serum and incubated at $37^{\circ} \mathrm{C}$ in a humidified incubator with $5 \% \mathrm{CO}_{2}$. On experiment, cells were cultured in serum-free medium in the presence or absence of $10 \mathrm{ng} / \mathrm{mL}$ TGF- $\beta 1$ (R\&D Systems, Minneapolis, MN).

To generate a stable miR-30a-expressing cell line, HMrSV5 cells were stably transfected with miR-30a expression vector or negative control vector (Genepharm, Shanghai) using the Lipofectamine LTX kit, according to the manufacturer's instructions (Invitrogen, Carlsbad, CA). The negative control vector contained a scrambled sequence in multiple cloning sites. Cells with stable expression of miR-30a were selected by addition of $10 \mu \mathrm{g} / \mathrm{mL}$ blasticidin for 7 days.

Primary peritoneal mesothelial cells were isolated from male Sprague-Dawley rats, as described previously. ${ }^{21}$ Cells were cultured in the same condition as HMrSV5 cells.

\section{Patients}

To evaluate the expression level of miR-30a in PD patients, peritoneal tissues were collected when performing the catheter insertion and exertion. Ten patients who were receiving CAPD over 3 months (from 3.5 to 66 months) were chosen as the PD group. Ten newly enrolled patients, when initially preparing for PD, were used as controls (never accept PD before). miRNA was extracted from the peritoneal tissue by using the mirVana miRNA Isolation Kit (Ambion, Austin, TX). The study was approved by the Institutional Review Board and Ethics Committee of The First Affiliated Hospital, Sun Yat-sen University. All of the participants had signed the informed consent form.

\section{Ultrasound-Microbubble-Mediated Gene Transfer of miR-30a Vector into the Peritoneum}

As described previously, ${ }^{18,22-24}$ an ultrasound-microbubble-mediated, miR-30a expression vector or negative control vector (the same vector as in vitro studies) was used in 
this study. All plasmids were prepared using the EndoFree Plasmid kit (Qiagen Inc., Valencia, CA), according to the manufacturer's instructions. Briefly, after mixing miR-30a with sulphur hexafluoride microbubbles (SonoVue; Bracco SpA, Milan, Italy) at a ratio of 1:1 (v/v), the mixed solution containing $1 \mathrm{mg}$ of designated plasmid in a total volume of 5 $\mathrm{mL}$ was injected into the peritoneal cavity. Immediately after injection, the ultrasound transducer (Chattanooga Medical Supply Inc., Chattanooga TN) was directly applied to the abdominal surface of skin coated with ultrasound media, and the pulse wave at the power output of $2.8 \mathrm{~W} / \mathrm{cm}^{2}, 3 \mathrm{MHz}$, was used. A total of 20-minute ultrasound treatment, with the continuous movement of the probe on the entire abdominal surface in a 10-minute interval at the face-up and face-down positions, was used. This movement allowed the ultrasound irradiation to reach the entire abdominal cavity containing the mixture of microbubbles. The same procedure was applied to the negative control animals. The study was approved by the Institutional Review Board/Ethics Committee of The First Affiliated Hospital, Sun Yat-sen University.

\section{Peritoneal Function Tests}

Peritoneal membrane function was evaluated by a 4-hour peritoneal equilibration test, as previously described. ${ }^{25}$ Briefly, for the peritoneal ultrafiltration rate, $25 \mathrm{~mL}$ of $4.25 \%$ dextrose PD solution was i.p. injected into each rat before being euthanized. Four hours later, the peritoneal fluid was removed for ultrafiltration measurement. Net ultrafiltration was the volume of fluid removed after 4 hours minus the volume of fluid administered. For the glucose transportation assay, we used $\mathrm{D} / \mathrm{D} 0$ of glucose, where $\mathrm{D}$ is the glucose concentration in the dialysate after 4 hours, and D0 is the glucose concentration in the PD solution before instillation into the peritoneal cavity.

\section{miRNA Microarray Analysis}

Total RNA was extracted from peritoneal tissues, and miRNA microarray was performed at CapitalBio Corp. (Beijing, China), as described previously. ${ }^{26}$ Briefly, total RNA was covalently labeled with $\mathrm{Cy} 3$ or $\mathrm{Cy} 5$, respectively. Pairs of labeled samples were hybridized to dual-channel microarrays. Dye switching was to eliminate dye bias. Fluorescent signals were measured by a double-channel laser scanner (LuxScan scanner, CapitalBio Corp.). The analog signal was transformed to a digital signal using image analysis software (LuxScan 3.0 software, CapitalBio Corp.). Raw data were normalized and analyzed using Significance Analysis of Microarrays software version 2.1 (Stanford University, Stanford, CA). ${ }^{27}$

\section{Bioinformatic Analysis}

miRNA target gene prediction was performed by four databases, including TargetScan (http://www.targetscan.org), PicTar (http://pictar.mdc-berlin.de), MicroCosm (http:// www.ebi.ac.uk/enright-srv/microcosm/htdocs/targets/v5), and miRanda (http://www.microrna.org/microrna/getMirna Form.do). Gene localization was searched on University of California, Santa Cruz, Genome Browser (http://genome. ucsc.edu/(cgi-bin/hgGateway).

\section{Real-Time PCR}

Total RNA and miRNA were isolated from peritoneal tissues or cells with TRIzol Reagent (Invitrogen) or the mirVana miRNA Isolation Kit. Expression of miRNAs was detected by the TaqMan microRNA assay (Applied Biosystems, Foster City, CA), according to manufacturer's instructions. The input was normalized by U6 snRNA. miR-30a and U6 primer sets were purchased from Applied Biosystems. Levels of miRNAs were normalized to U6 snRNA in each sample and calculated using the $2^{-\Delta \Delta C}$ method, based on the mean $\mathrm{C}_{\mathrm{T}}$ value, calculated as follows: $\Delta \Delta \mathrm{C}_{\mathrm{T}}=\left[\mathrm{C}_{\mathrm{T}}\right.$ (Target) $\left.\mathrm{C}_{\mathrm{T}}(\mathrm{U} 6)\right]$ Sample $-\left[\mathrm{C}_{\mathrm{T}}(\right.$ Target $\left.)-\mathrm{C}_{\mathrm{T}}(\mathrm{U} 6)\right]$ Control. ${ }^{27}$ For the detection of Snail mRNA, total RNA was reverse transcripted to cDNA by RevertAid H Minus First Strand cDNA Synthesis Kit (Fermentas, Hanover, MD) and subsequently amplified by PCR using the following primers: forward, 5'-GAGTGGTTCTTCTGCGCTAC-3'; and reverse, 5'-AGGGCTGCTGGAAGGTAAACT- $3^{\prime}$. An endogenous control gene, glyceraldehyde-3-phosphate dehydrogenase (GAPDH), was amplified using the following primers: forward, $5^{\prime}$-CAACGGATTTGGTCGTAT-3'; and reverse, 5'-AGCCTTCTCCATGGTGGTG- $3^{\prime}$. Relative quantification of gene expression was performed using the $2^{-\Delta \Delta C}$ method based on $\mathrm{C}_{\mathrm{T}}$ values for both target and reference genes. ${ }^{27}$ Three independent experiments were performed, and the results were given as means $\pm \mathrm{SD}$.

\section{Histopathological and Immunofluorescent Examination}

Histologically, paraffin sections ( $3 \mu \mathrm{m}$ thick) from the anterior abdominal wall were stained with Masson's trichrome. The thickness $(\mu \mathrm{m})$ of the peritoneum was measured in each group using a micrometer fitted into the eyepiece of the microscope and expressed as the means \pm SD. Each section was measured at five random sites.

Immunohistologically, paraffin sections ( $6 \mu \mathrm{m}$ thick) from the visceral peritoneum were cut and dehydrated in xylene, followed by antigen retrieval in R-buffer A (EM Science, Hatfield, PA) by autoclave (ProteoGenix, Obershausbergen, France). Sections were then blocked with PBS containing 3\% bovine serum albumin for 30 minutes at $37^{\circ} \mathrm{C}$. Sections were incubated overnight at $4^{\circ} \mathrm{C}$ with the indicated primary antibodies diluted in $1 \%$ bovine serum albumin in PBS and Alex488 secondary antibody (Invitrogen) for 1 hour at $37^{\circ} \mathrm{C}$.

For immunofluorescent examination, the cultured HMrSV 5 cells on 10-mm coverslips (EM Science, Hatfield, PA) were fixed in PBS containing 4\% paraformaldehyde and $0.1 \%$ Triton X-100 (EMD, Darmstadt, Germany) for 10 minutes at room temperature for 10 minutes at $4^{\circ} \mathrm{C}$ and then 


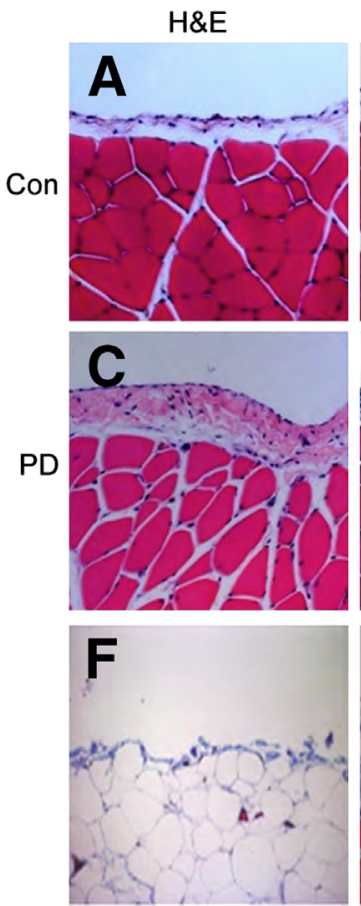

New
Masson

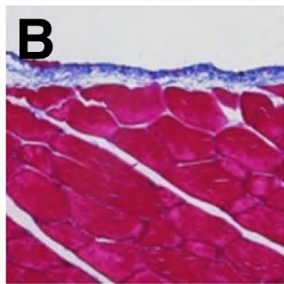

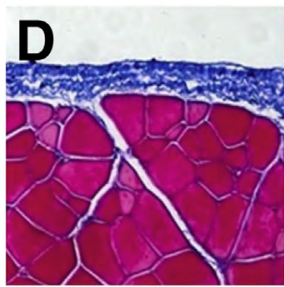

E
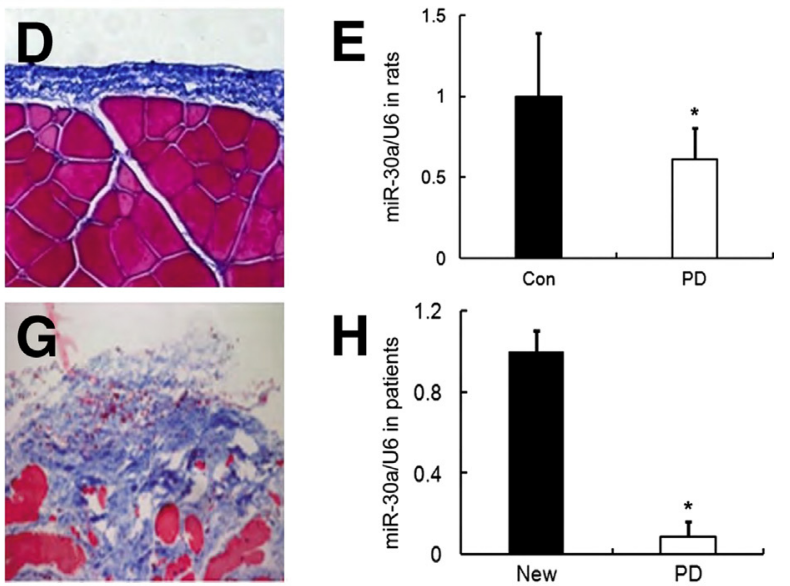

PD

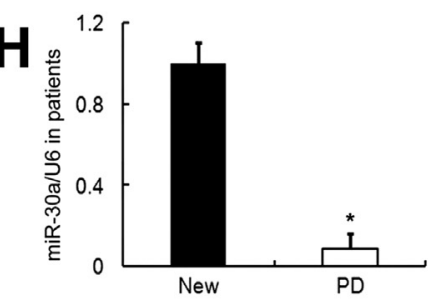

Figure 1 miR-30a is down-regulated in peritoneal tissues with fibrosis in a rat model of $\mathrm{PD}$ and in patients with CAPD. H\&E (A and C) and Masson's trichrome (B and $\mathbf{D})$ staining shows severe peritoneal fibrosis in a rat model of PD. E: Real-time PCR shows that miR-30a is significantly down-regulated in rat peritoneal tissues after PD. Data represent means \pm SD for eight rats in each group. ${ }^{*} P<0.05$ when compared with control (Con) rats. F: Masson's trichrome staining shows an example of peritoneal tissue without peritoneal fibrosis from a newly enrolled patient before PD. G: Masson's trichrome staining shows an example of severe peritoneal fibrosis in a patient who had been undergoing dialysis for $>1$ year. $\mathbf{H}$ : Real-time PCR detects a marked down-regulation of miR-30a in the peritoneal tissue after PD for 3.5 to 66 months. ${ }^{*} P<0.05$ compared with those newly enrolled patients before PD $(n=10$ in each group). Original magnification, $\times 200(\mathbf{A}-\mathbf{D}, \mathbf{F}$, and $\mathbf{G}$ ). in $-20^{\circ} \mathrm{C}$ methanol for 1 minute. ${ }^{28}$ After washing with PBS, cells were blocked with PBS containing $5 \%$ bovine serum albumin and $10 \%$ goat serum for 30 minutes at $37^{\circ} \mathrm{C}$. Cells were incubated overnight at $4{ }^{\circ} \mathrm{C}$, with the indicated primary antibodies diluted in the blocking solution, and then incubated with Alex-546 secondary antibody (Invitrogen) for 1 hour at $37^{\circ} \mathrm{C}$. Samples were mounted in anti-fading mounting medium (EM Science, Hatfield, PA). DAPI (Sigma-Aldrich, St. Louis, MO) was used to stain the nucleus. Images were analyzed and collected with a Zeiss LSM 510 Confocal Imaging System (Zeiss, Jena, Germany).

\section{Western Blot Analysis}

For Western blot analysis, the cell lysate was subjected to SDSPAGE and transferred to a nitrocellulose membrane. Protein expression was analyzed by Western blot analysis with primary antibody against $\alpha$-SMA (Dako, Glostrup, Denmark), E-cad (BD Biosciences, San Diego, CA), Col I (SouthernBiotech, Birmingham, AL), cytokeratin-18 (Sigma-Aldrich), or Snai1 (Cell Signaling Technology, Danvers, MA) and then incubated with an appropriate secondary antibody. After washing, the protein was visualized with Super Signal Western Pico chemiluminescent substrate (Pierce, Rockford, IL), and signals were detected by an Odyssey Detection System (Li-COR, Lincoln, NE). The relative protein levels of Col I, E-cad, $\alpha-$ SMA, and Snail were normalized to GAPDH, and then the ratio was compared with that of the control group.

\section{Luciferase Reporter Assay}

For construction of the $3^{\prime}$ untranslated region (UTR) of Snai1 reporter plasmids, the 796 bp of Snail 3' UTR was amplified by PCR and then cloned into pGL3 luciferase vector (Promega, Madison, WI) at the XbaI-digested site. The Snai1 3' UTR was constructed using the following oligonucleotide: sense, 5'-ATTCTAGACGAGGCTCCCTCTTCCTCTCCA-3'; and antisense, 5'-GCTCTAGAAATATCAATAAACTGTACATAT- $3^{\prime}$. Furthermore, the mutation of Snai1 $3^{\prime}$ UTR was established by replacing four nucleotides in the miR-30a binding site by using the QuikChange site-directed mutagenesis kit (Promega). Primers used for PCR were as follows: sense, 5'-CTGGGAGGAAGATGAAGCCATTTTTAAAGGTA- ${ }^{\prime}$; and antisense, 5'-TACCTTTAAAAATGGCTTCATCTTCCTCCCAG- $3^{\prime}$. The underlined sequence indicated the mutated binding site for miR-30a. HMrSV5 cells were plated in 48well plates, then $200 \mathrm{ng}$ of pGL3-control luciferase reporter (Promega) with $10 \mathrm{ng}$ of the pRL-TK vector (Promega) and $500 \mathrm{ng}$ of miR-30a or negative control vector (Genepharm) were cotransfected using Lipofectamine LTX with PLUS Reagent (Invitrogen). The luciferase assay was performed at 48 hours after transfection by using the Dual-Luciferase Reporter Assay System (Promega) on a Luminometer (Berthold, Pforzheim, Germany). Renilla luciferase activity was normalized to firefly luciferase expression for each sample. Data were given as means \pm SD of three independent experiments and shown as the ratio of firefly luciferase activity/renilla.

\section{Cell Migration Assay}

A wound healing assay was performed to study the migratory property of cells in response to TGF- $\beta 1$. A scratch was made using a 1-mL pipette tip (Axygen, Union City, CA), and then 
Table 1 Statistical Results and Putative Targets of the Set of miRNAs Differentially Expressed in Rats with Peritoneal Fibrosis Compared with Negative Control Rats

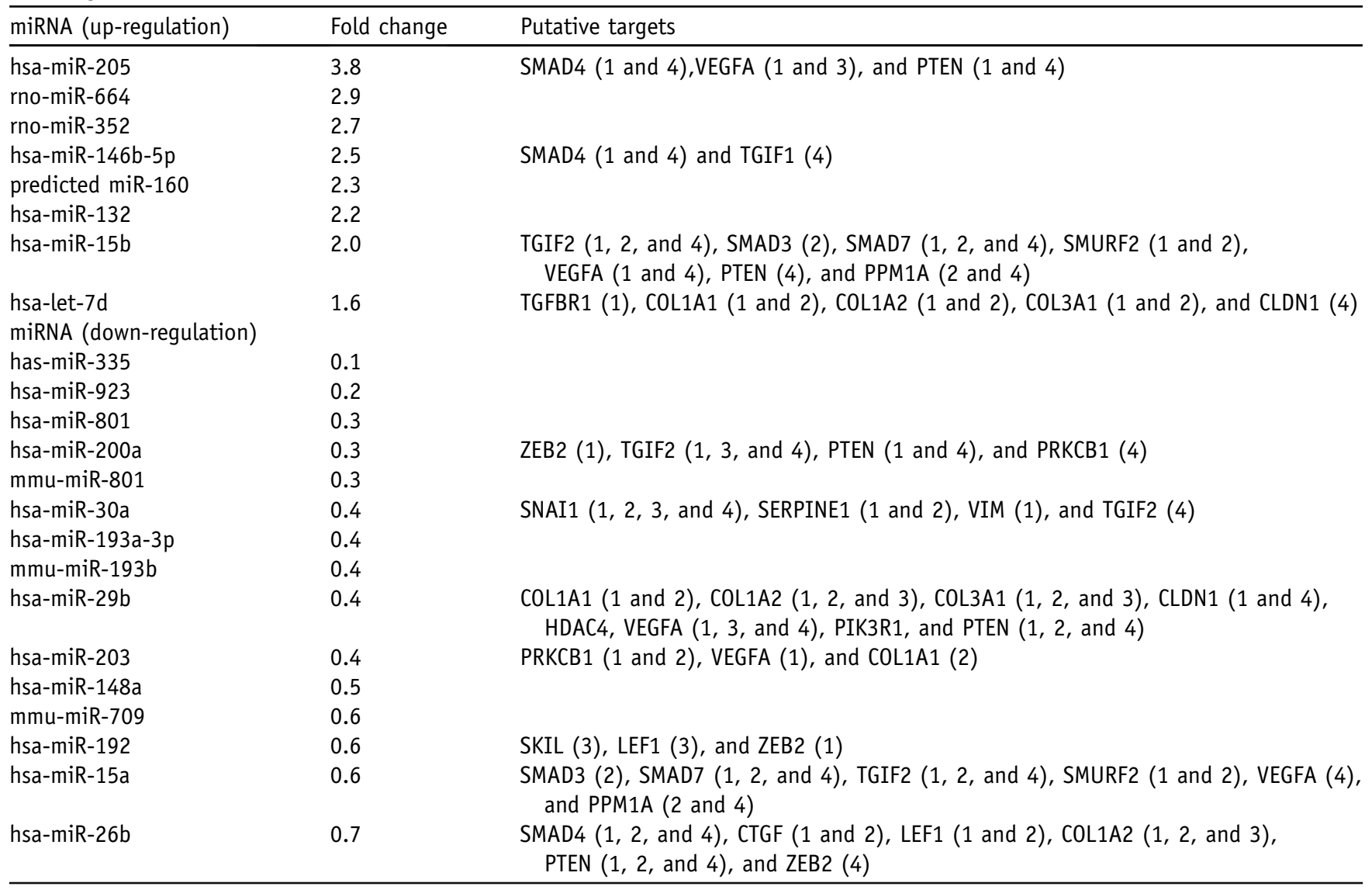

Putative targets were predicted by TargetScan (1), PicTar (2), MicroCosm (3), and miRanda (4). Website addresses are given in Bioinformatic Analysis.

CLDN1, claudin-1; COL1A1, collagen type I, $\alpha 1$ chain; COL1A2, collagen type I $\alpha$ 2; COL3A1, collagen type III, $\alpha 1$ chain protein; CTGF, connective tissue growth factor; HDAC4, histone deacetylase 4; LEF1, lymphoid enhancer factor-1; PIK3R1, phosphatidylinositol 3-kinase, regulatory subunit 1; PPM1A, Smad2/3 phosphatase; PRKCB1, protein kinase C, $\beta$ 1; PTEN, lipid phosphatase regulator of PKB/Akt activation; SERPINE1, plasminogen activator inhibitor 1 (PAI-1); SKIL, V-SKI avian sarcoma viral oncogene homolog; SMURF2, Smad ubiquitination regulatory factor-2 (Smurf2), an E3 ubiquitin ligase; SNAI1, SNAIL, drosophila, homolog 1; TGIF (TG-interacting factor), an Smad transcriptional corepressor; VEGFA, vascular endothelial growth factor A; VIM, vimentin; ZEB2, zinc finger $\mathrm{E}$ box-binding homeobox 2.

cells were washed in PBS twice to remove the dead cells. The width of cell-free space was measured after $10 \mathrm{ng} / \mathrm{mL}$ TGF$\beta 1$ treatment for 0,12 , and 24 hours by microscope (Zeiss).

Cell migration was evaluated using a Boyden chamber motility assay with Transwell filters (Millipore, Billerica, MA). Transwells $(8-\mu \mathrm{m}$ pore size, $6.5 \mathrm{~mm})$ were coated with collagen solution (Sigma-Aldrich) overnight at $4^{\circ} \mathrm{C}$. Stably transfected HMrSV5 cells were initially cultured on 35-mm dishes. After stimulating with or without $10 \mathrm{ng} / \mathrm{mL}$ TGF- $\beta 1$ for 48 hours, $1 \times 10^{4}$ cells were resuspended and seeded onto the filters of the wells containing the same medium with $10 \mathrm{ng} / \mathrm{mL}$ TGF- $\beta 1$ as a chemotactic factor in the compartment. After 15 hours of incubation at $37^{\circ} \mathrm{C}$, filters were fixed with methanol for 15 minutes at room temperature and stained with $1 \%$ crystal violet for another 15 minutes, and the upper surface of the filters was carefully wiped with a cotton-tipped applicator. Cells that passed through the pores were counted in three nonoverlapping fields and imaged (Zeiss). The percentage of migrated cells was calculated by counting the total number of migrated cells from three nonoverlapping fields in each experiment and then dividing by the cell numbers seeded $(1 \times$ $10^{4}$ cells). Three independent experiments were performed.

\section{Statistical Analysis}

Data obtained from this study were expressed as means \pm $\mathrm{SD}$, and the statistical significance was analyzed using a oneway analysis of variance and an unpaired $t$-test (GraphPad Prism, version 5.01). Differences were considered statistically significant at $P<0.05$.

\section{Results}

miR-30a Is Down-Regulated during Peritoneal Fibrosis in a Rat Model of PD and in Patients with CAPD

To investigate whether miRNAs are involved in the pathogenesis of peritoneal fibrosis, we examined miRNA 
Table 2 Patient Characteristics

\begin{tabular}{lll}
\hline Characteristics & PD $(n=10)$ & New $(n=10)$ \\
\hline $\begin{array}{l}\text { Male/female ratio } \\
\text { Age (years) }\end{array}$ & $7: 3$ & $3: 7$ \\
$\quad$ Mean \pm SD & $45.9 \pm 17.7$ & $57.0 \pm 13.4$ \\
$\quad$ Median (range) & $50.0(16.7-68.8)$ & $51.5(37.0-73.6)$ \\
Total time in PD (months) & & \\
$\quad$ Mean \pm SD & $33.3 \pm 21.5$ & 0 \\
$\quad$ Median (range) & $34.1(3.5-66.0)$ & 0 \\
Cause of PD dropout & & \\
$\quad$ Peritonitis & 3 & 0 \\
$\quad$ Inadequate dialysis & 3 & 0 \\
$\quad$ Technique failure & 1 & 0 \\
$\quad$ Heart failure & 1 & 0 \\
$\quad$ Renal transplantation & 2 & 0 \\
\hline
\end{tabular}

New, newly enrolled patients before PD; PD, CAPD patients who had been undergoing dialysis from 3.5 to 66 months.

expression profiles in peritoneal tissues with or without fibrosis. We found that peritoneal fibrosis with a massive extracellular matrix accumulation was developed in a rat model of chronic PD (Figure 1, A-D). By miRNA microarray analysis, we found that, in peritoneal tissues with fibrosis, eight miRNAs were up-regulated, whereas 15 miRNAs were down-regulated (Table 1). Among them, down-regulation of the miR-30a was particularly interesting because miR-30a is known to target the EMT-related genes, such as Snai1 and vimentin. ${ }^{25,29}$ Down-regulation of miR-30a in the fibrotic peritoneal tissues was also validated by real-time PCR (Figure 1E), suggesting that miR-30a may negatively regulate peritoneal fibrosis.

We next tested whether miR-30a is lost in fibrotic peritoneal tissues in patients undergoing PD and in those with new enrollment before PD by real-time PCR. The characteristics of patients and the causes of catheter removal from those undergoing PD were described in Table 2. Compared with the newly enrolled patients before PD in whom no remarkable peritoneal fibrosis was evident, patients with PD developed severe peritoneal fibrosis with abundant extracellular matrix accumulation (Figure 1, F and G), which was associated with a marked reduction in miR-30a (Figure $1 \mathrm{H}$ ).

\section{miR-30a Is Down-Regulated by TGF- $\beta 1$ during EMT in Vitro}

Because EMT has been shown as one of the important mechanisms during the pathogenesis of peritoneal fibrosis, ${ }^{1}$ we next examined whether down-regulation of miR-30a contributes to TGF- $\beta 1-$ induced EMT in peritoneal mesothelial cells. Incubation of HMrSV5 cells and rat primary peritoneal mesothelial cells with $10 \mathrm{ng} / \mathrm{mL}$ TGF- $\beta 1$ for 48 hours resulted in a remarkable loss of the cobblestone-like growing appearance and the gain of elongated fibroblast-like morphological features (Figure 2A). This morphological change of HMrSV5 cells was associated with down-regulation of E-cad, but a marked up-regulation of $\alpha$-SMA and Col I expression (Figure 2, A and B, and Supplemental Figure S1, $\mathrm{B}-\mathrm{E})$. Similar results were obtained in primary rat peritoneal mesothelial cells (Figure 2A and Supplemental Figure S1F). More important, TGF- $\beta 1$-induced EMT in both HMrSV5 cells and primary culture of rat peritoneal mesothelial cells was associated with up-regulation of Snail at both the protein (Figure 2B) and mRNA (Figure 2C) levels, but downregulation of miR-30a (Figure 2, D and E).

\section{Overexpression of miR-30a Attenuates \\ TGF- $\beta 1$-Induced EMT, Fibrogenesis, and Migrating Activity by HPMCs}

To determine the functional role of miR-30a in the process of EMT and peritoneal fibrosis, HMrSV5 cells were stably transfected with the miR-30a expression vector or negative control vector. Real-time PCR, Western blot analysis, and immunofluorescence detected that overexpression of

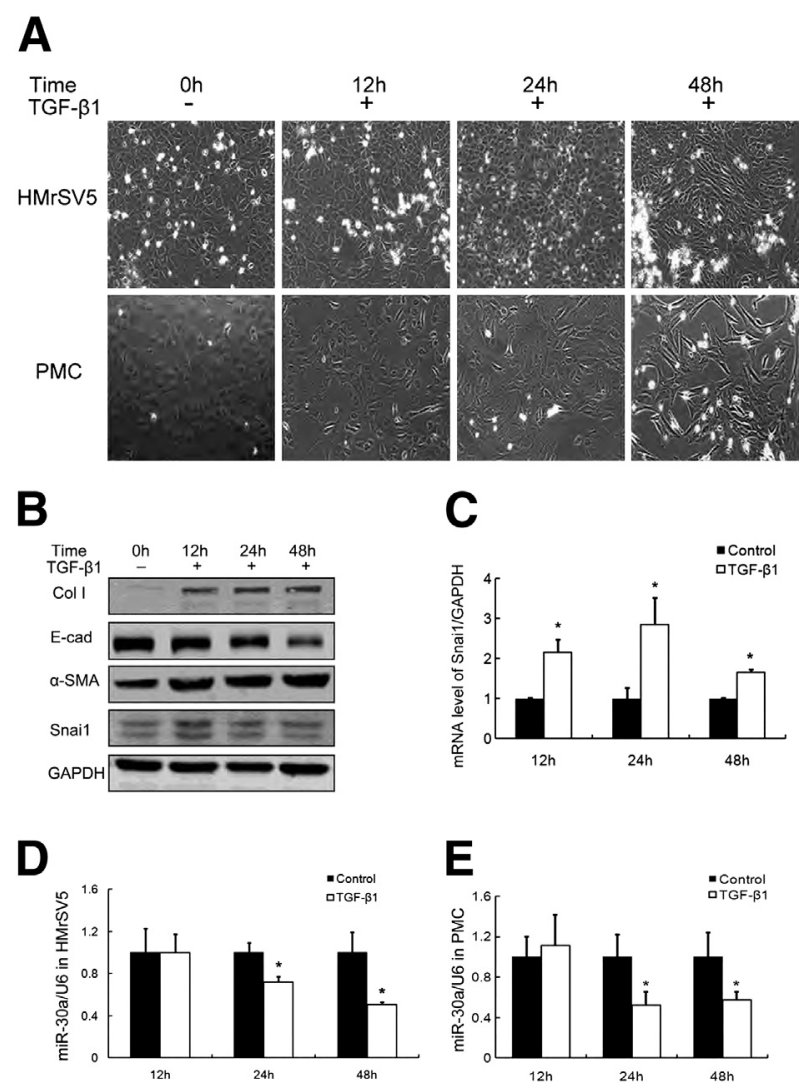

Figure $2 \mathrm{miR}-30 \mathrm{a}$ is down-regulated during peritoneal fibrosis induced by TGF- $\beta 1$ in peritoneal mesothelial cells. A: Morphological change of HMrSV5 cells (top panels) and rat primary peritoneal mesothelial cells (PMCs; bottom panels) after $10 \mathrm{ng} / \mathrm{mL}$ TGF- $\beta 1$ treatment for $0,12,24$, and 48 hours. B: Western blot analysis of $10 \mathrm{ng} / \mathrm{mL}$ TGF- $\beta 1$-induced Col I expression, EMT (reduced E-cad and gained $\alpha$-SMA), and up-regulation of Snai1 in HMrSV5 cells in a time-dependent manner. C: Real-time PCR detected that addition of $10 \mathrm{ng} / \mathrm{mL}$ TGF- $\beta 1$ up-regulated Snai1 mRNA expression in $\mathrm{HMrSV} 5$ cells significantly. $\mathbf{D}$ and $\mathbf{E}$ : Real-time PCR showed 10 $\mathrm{ng} / \mathrm{mL}$ TGF- $\beta 1$-induced down-regulation of miR-30a in HMrSV5 cells (D) and PMCS (E) at 24 and 48 hours. Data represent means \pm SD for three independent experiments. ${ }^{*} P<0.05$ versus control. 
A
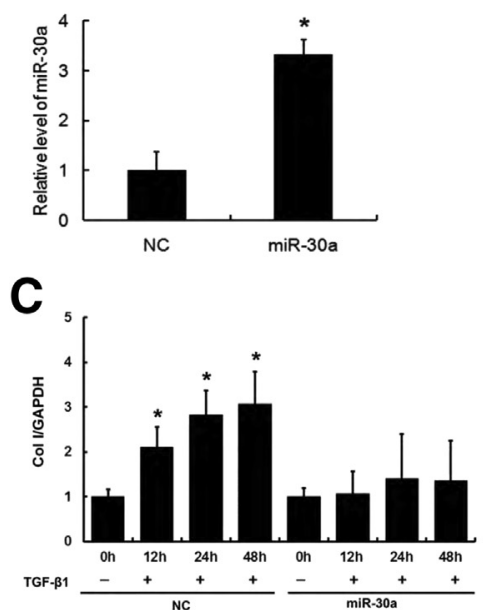

E

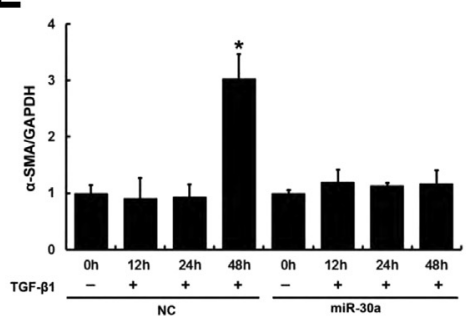

B

D
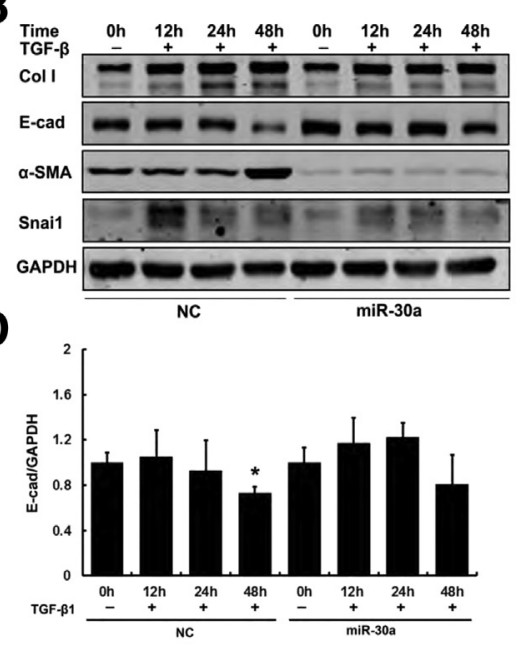

$\mathbf{F}$

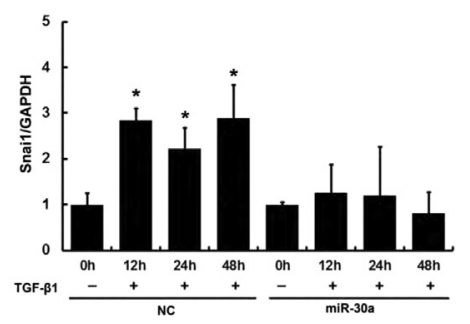

H
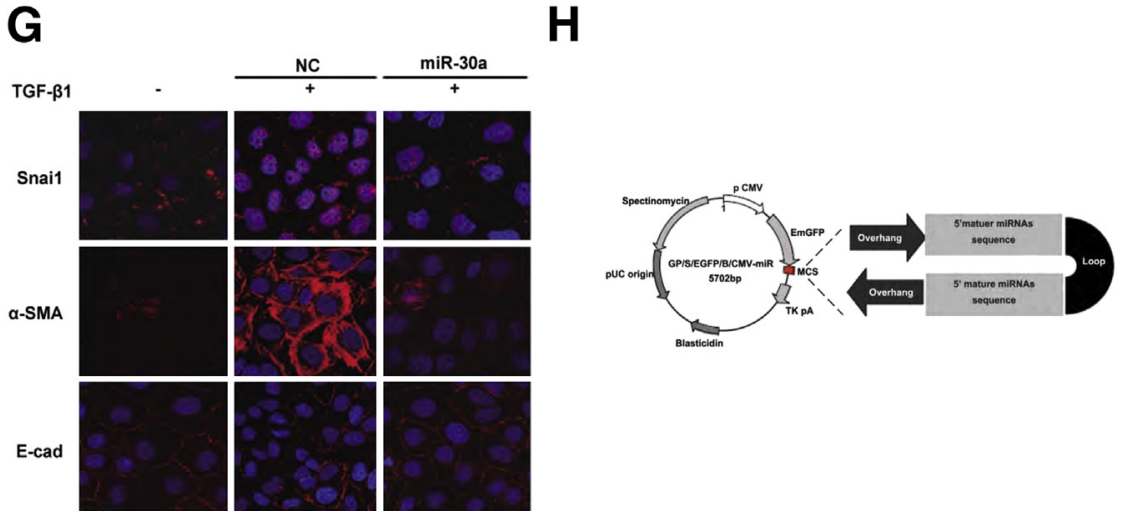

Figure 3 Overexpression of miR-30a inhibits TGF- $\beta 1-$ induced EMT and peritoneal fibrosis in HMrSV5 cells. A: Real-time PCR shows that HMrSV5 cells stably transfected with miR-30a have high levels of miR-30a expression. ${ }^{*} P<0.05$ compared to NC groups. B: Western blot analysis shows that overexpression of miR-30a inhibits $10 \mathrm{ng} / \mathrm{mL}$ TGF- $\beta 1$-induced up-regulation of Col I, EMT (reduced E-cad and gained $\alpha$-SMA), and Snai in a time-dependent manner. $\mathbf{C}-\mathbf{F}$ : Quantitative data of relative protein level of Col I, E-cad, $\alpha$-SMA, and Snai1 in TGF- $\beta 1$-treated cells (normalized to $G A P D H)$. Data represent means \pm SD for three independent experiments. ${ }^{*} P<0.05$ compared with time 0 hours in the NC and miR-30a groups. G: Immunofluorescence shows that overexpression of miR-30a inhibits TGF- $\beta 1$-induced $(10 \mathrm{ng} / \mathrm{mL}$, treated for 48 hours) up-regulation of Snai1 and EMT marker (red) in HMrSV 5 cells. Nuclei are stained by DAPI (blue). Original magnification, $\times 630$. H: Structure of miR30a expression vector. The matured sequence of miR-30a was cloned into the multiple cloning site (MCS) of the vector. miR-30a, miR-30a plasmid stable transfection; NC, negative control plasmid transfection.
miR-30a significantly blocked TGF- $\beta 1-$ induced EMT and Col I expression (Figure 3). Furthermore, we also examined the inhibitory effect of miR-30a on the cell migrating activity because cells undergoing the EMT process have higher mobility. As shown in Figure 4, overexpression of miR-30a on HMrSV5 cells significantly blocked TGF$\beta 1$-induced cell migrating activity, as determined by wound healing and Transwell assay (Figure 4, A-C). All these results demonstrated that miR-30a may be a key regulator that negatively regulates TGF- $\beta 1$-induced EMT and peritoneal fibrosis.

\section{miR-30a Targets Snai1-Mediated EMT in Response to} TGF- $\beta 1$

Because Snai1 is an important transcript factor in EMT, ${ }^{17}$ we investigated whether the inhibitory effect of miR-30a on EMT in HPMCs is Snail dependent. As shown in Figure 2, TGF- $\beta 1$-induced EMT and Col I expression in HMrSV5 cells was associated with a marked up-regulation of Snail at both the protein and mRNA levels, which was associated with a loss of miR-30a expression (Figure 2D). In contrast, overexpression of miR-30a blocked TGF- $\beta 1-$ induced Snail expression, resulting in inhibition of EMT and Col I expression (Figure 3, B-F).

To validate the interaction between Snail and miR30a, a 796-bp fragment of $3^{\prime}$ UTR of the Snail sequence was cloned into the $3^{\prime}$ end of the luciferase gene in the reporter vector, pGL3 (Figure 5A). To confirm the interaction between Snail and miR-30a, we mutated the predicted binding site of miR-30a in the $3^{\prime}$ UTR of Snai1. As shown in Figure 5B, overexpression of miR$30 \mathrm{a}$ in HMrSV5 cells attenuated the activity of wildtype Snai1 $3^{\prime}$ UTR reporter to $35 \%$, which was not 


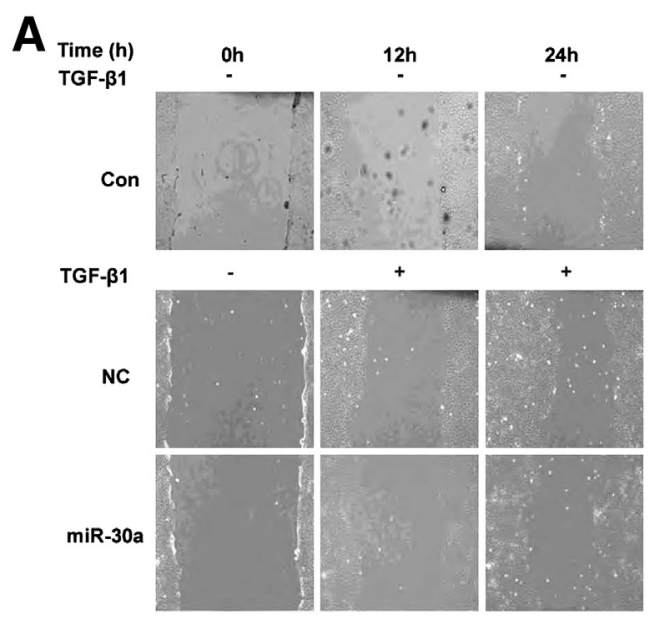

B

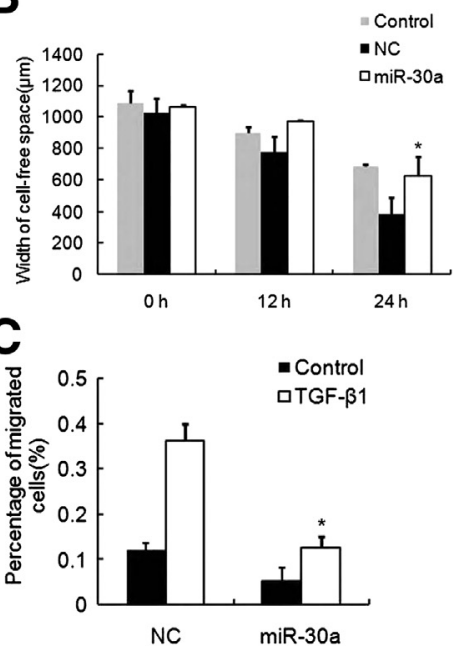

Figure 4 Overexpression of miR-30a inhibits TGF- $\beta 1$-induced migrating activities in HMrSV 5 cells. A: Representative images of the woundhealing assay. HMrSV5 cells were treated with 10 $\mathrm{ng} / \mathrm{mL}$ TGF- $\beta 1$ for 0,12 , and 24 hours. Top panels: Control cells without TGF- $\beta 1$ treatment. Middle panels: Cells stably expressing negative control vector (NC) and treated by TGF- $\beta 1$. Botttom panels: Data from cells stably overexpressing miR$30 \mathrm{a}$ and treated with TGF- $\beta 1$. Original magnification, $\times 100$. B: Quantitative analysis of the width of cell-free space post-scratch at 0,12 , and 24 hours. Results show that overexpression of miR30a inhibits $10 \mathrm{ng} / \mathrm{mL}$ TGF- $\beta 1$-induced cell migration of HMrSV5 cells at 24 hours. ${ }^{*} P<0.05$ compared with NC TGF- $\beta 1$ treated cells at 24 hours. C: The percentage of migrated HMrSV5 cells is measured by Transwell assay. Data represent means \pm SD for three independent experiments. ${ }^{*} P<0.05$ compared with NC TGF- $\beta 1-$ treated cells. found in the mutant Snai1 3' UTR reporter. Interestingly, Western blot analysis and real-time PCR showed that miR-30a overexpression dramatically down-regulated the protein level of Snail (Figure 5, D and E), but did not alter its mRNA level (Figure 5C), demonstrating that miR-30a repressed the translation of Snai1, but did not induce degradation of Snail mRNA.
miR-30a Gene Transfer Protects the Peritoneal Membrane from PD-Induced Peritoneal Fibrosis in Vivo

We next determined the functional role of miR-30a in a rat model of peritoneal fibrosis. First, real-time PCR was used to determine the duration of miR-30a transgene expression within the peritoneal tissues mediated by ultrasound-microbubble

A

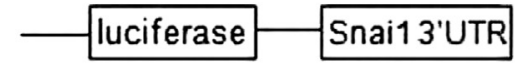

\section{Snai1 3' UTR mutant ...GGCCUGGGAGGAAGAUGAAGCCA... \\ Snai1 3' UTR ...GGCCUGGGAGGAAGAUGUUUACA... \\ hsa-miR-30a \\ GAAGGUCAGCUCCUACAAAUGU}

B

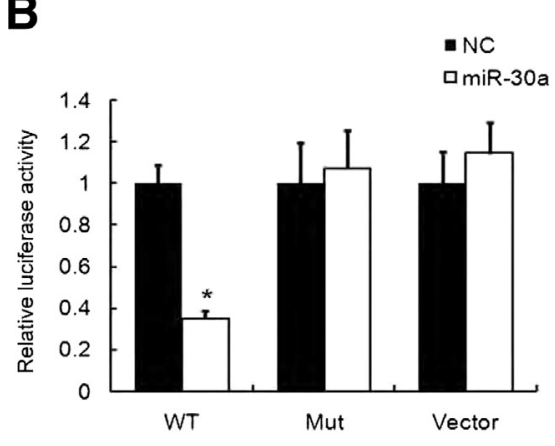

D

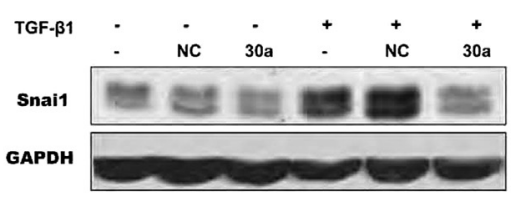

seed region
C

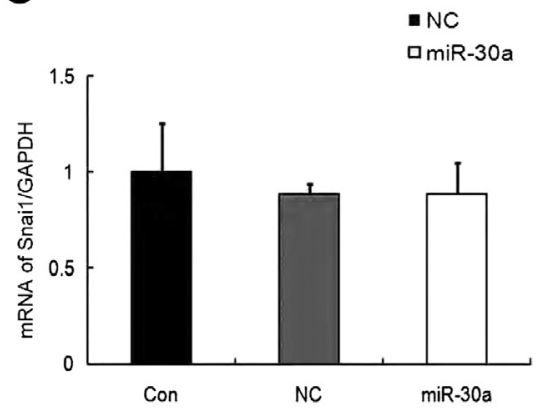

$E$

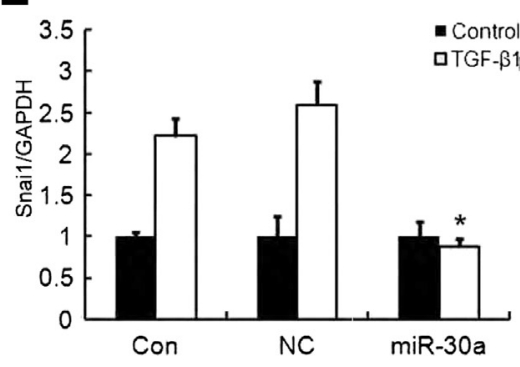

Figure 5 Overexpression of miR-30a inhibits TGF- $\beta 1$-induced Snai1 expression in HMrSV5 cells. A: The schematic luciferase reporter constructs. A mutant construct was made by replacing four nucleotides in the miR-30a seed binding site of the Snai1 $3^{\prime}$ UTR. Mutated nucleotides were marked in gray. B: The luciferase reporter assay of Snai1 $3^{\prime}$ UTR reporter in HMrSV5 cells at 48 hours after transfection. ${ }^{*} P<0.05$ versus NC or miR-30a mutant. C: Real-time PCR shows that Snai1 mRNA expression is not changed at 48 hours after NC or miR-30a transfection. D: Western blot analysis of the inhibitory effect of miR-30a on $10 \mathrm{ng} / \mathrm{mL}$ TGF$\beta 1$-induced Snai1 protein expression at 48 hours. Results show that overexpression of miR-30a inhibits $10 \mathrm{ng} / \mathrm{mL}$ TGF- $\beta 1$-induced Snai1 protein level. HMrSV5 cells were transiently transfected with miR-30a or NC plasmid. E: Quantitative data of the relative protein level of Snai1 in TGF- $\beta 1-$ treated cells (normalized to GAPDH). Data represent means \pm SD for three independent experiments. Con, control; miR-30a, miR-30a plasmid transient transfection; Mut, mutant of the potential binding site in the $3^{\prime}$ UTR of Snai1; NC, negative control plasmid; Vector, empty pGL3-control vector; WT, wild-type Snail $3^{\prime}$ UTR. ${ }^{*} P<0.05$ versus the TGF- $\beta 1-$ treated NC group. 

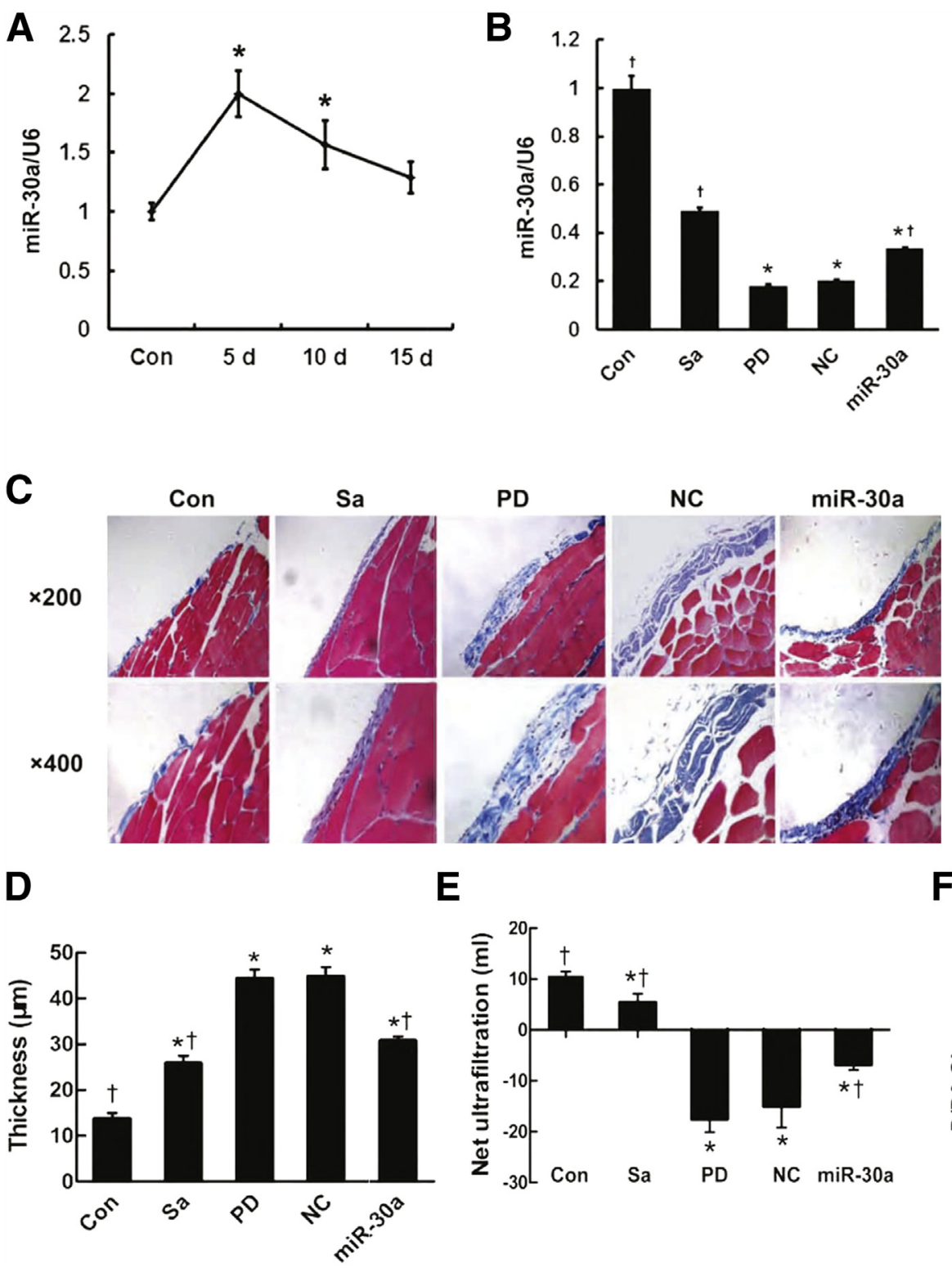

E

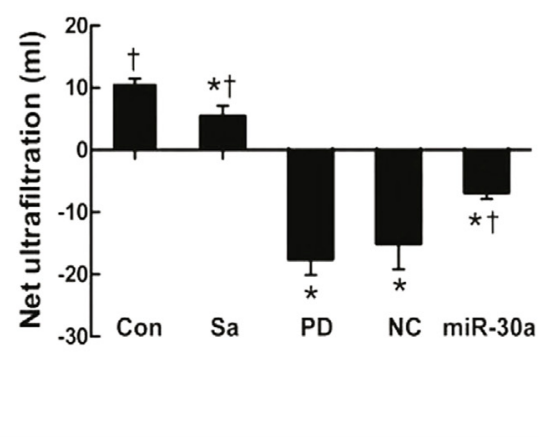

Figure 6 miR-30a transfer protects the peritoneal membrane from $\mathrm{PD}$-induced fibrosis. $\mathrm{A}$ : Real-time PCR shows the level of miR-30a in peritoneum from rats after ultrasound-microbubble-mediated gene transfer from 0 to 15 days. Transfection of miR-30a plasmid maintains higher levels of miR-30a expression from 5 to 10 days, but gradually reduces levels at day 15 after transfer. Data represent means \pm SD for three rats in each group. B: Real-time PCR shows high levels of miR$30 \mathrm{a}$ in rats that received miR-30a treatment at 4 weeks. C: Masson's trichrome staining shows that overexpression of miR-30a inhibits PD-induced peritoneal fibrosis. D: Quantitative analysis of the thickness of the peritoneum in Masson's trichrome staining. E: Overexpression of miR-30a prevents a loss of peritoneal function after PD for 4 weeks. The net ultrafiltration rate was calculated by the volume of fluid removed after 4 hours minus the volume of fluid administered (25 $\mathrm{mL})$. F: Peritoneal function was assessed by the transfer of glucose (D/D0). Con, normal rats; miR30 a and NC, daily PD and treated with miR-30a or NC plasmid at 1, 10, and 20 days; PD, daily i.p. injections of $4.25 \%$ dextrose PD solution for 4 weeks; Sa, saline treatment for 4 weeks. ${ }^{*} P<0.05$ compared with normal control (Con); ${ }^{\dagger} P<0.05$ compared with the PD group. Data represent means \pm SD for five rats in each group.
$\mathbf{F}$

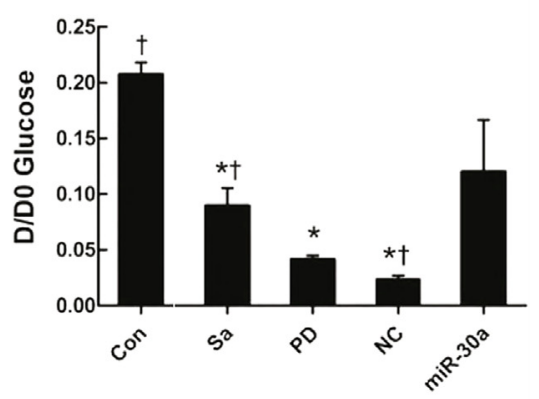

technique. As shown in Figure 6A, ultrasound-microbubble-mediated miR-30a gene transfer resulted in higher levels of miR-30a expression over 5 to 10 days, which declined to no significant levels at day 15 . Thus, to maintain the higher levels of miR-30a within the peritoneal tissues, miR-30a gene transfer was performed in a 10-day interval until animals were euthanized at day 28 after PD.

Real-time PCR showed that the PD animals treated with miR-30a gene transfer had a nearly twofold up-regulation of miR-30a when compared with those that received control treatment (Figure 6B). An increase in expression of peritoneal miR-30a resulted in a significant attenuation of peritoneal fibrosis, as demonstrated by Masson's trichrome staining, thereby largely preventing a loss of peritoneal function, as demonstrated by preserving the net ultrafiltration rate (Figure 6, C-E). However, the mass transport of glucose did not reach to statistical significance (Figure 6F). This may be associated with individual variation in the glucose metabolic rate and solute transport efficiency, as previously described in human and animal studies. ${ }^{30,31}$

Furthermore, we found that the protective effect of miR30a on peritoneal fibrosis was also associated with the blockade of EMT, as demonstrated by preventing the loss of epithelial and mesothelial markers, including E-cad and cytokeratin-18, and the gain of a mesenchymal marker, $\alpha$-SMA, resulting in inhibition of peritoneal collagen matrix accumulation (Figure 7, A and B). Similar to the results seen in an in vitro study, the therapeutic effect of miR-30a on peritoneal fibrosis in vivo was also associated with the inhibition of Snail (Figure 7, B and F). 


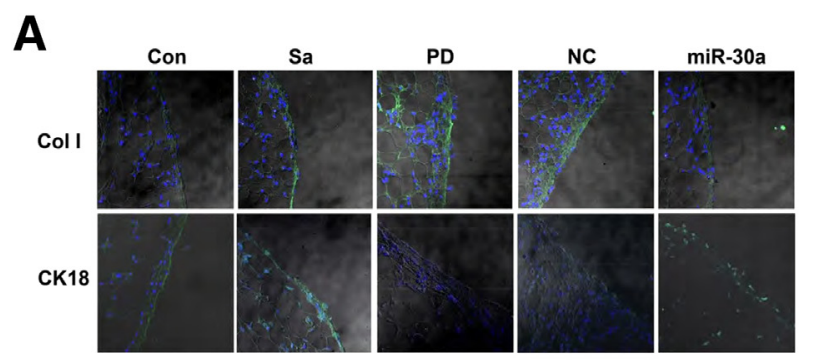

B

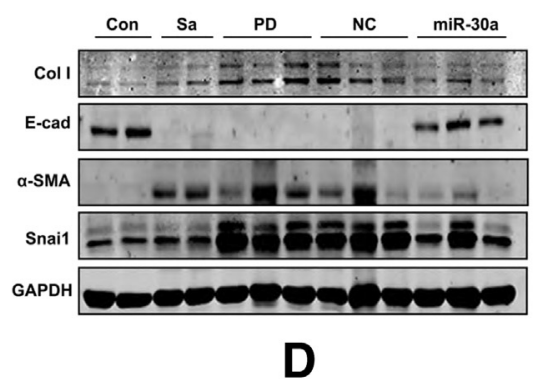

C
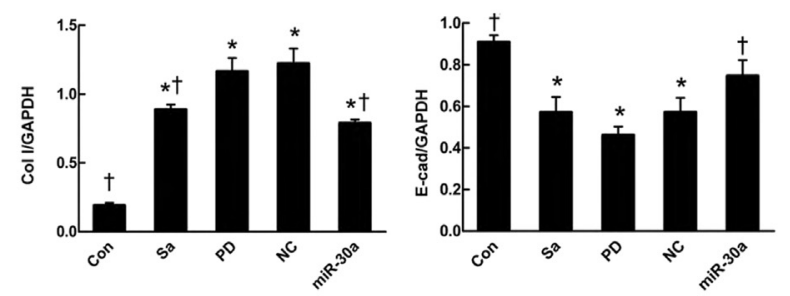

E

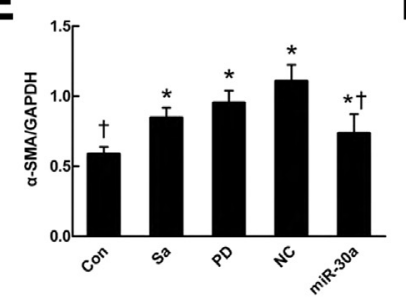

$\mathbf{F}$

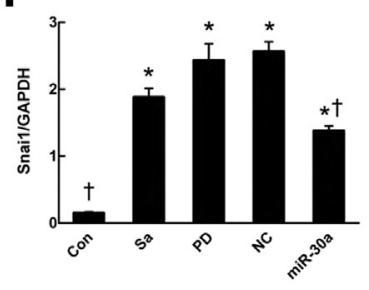

Figure 7 miR-30a transfer protects the peritoneal membrane from PDinduced fibrosis. A: Confocal microscopy detects that miR-30a gene transfer inhibits PD-induced Col I (green) accumulation and the loss of cytokeratin18 (CK-18; green) expression. Nuclei are stained by DAPI (blue). Original magnification, $\times 400$. B: Western blot analysis shows that overexpression of miR-30a inhibits PD-induced up-regulation of Col I, $\alpha$-SMA, and Snai1, and down-regulation of $\mathrm{E}$-cad in rats. $\mathbf{C}-\mathbf{F}$ : Quantitative analysis of relative protein level of Col I, E-cad, $\alpha$-SMA, and Snai1 (normalized to GAPDH). Data represent means \pm SD of five rats in each group. Con, normal rats; miR-30a and NC, daily PD and treated with miR-30a or NC plasmid at 1, 10, and 20 days; PD, daily i.p. injections of $4.25 \%$ dextrose PD solution for 4 weeks; Sa, saline treatment for 4 weeks. ${ }^{*} P<0.05$ compared with normal control (Con); ${ }^{\dagger} P<0.05$ compared with the PD group. Data represent means \pm SD for five rats in each group.

\section{Discussion}

Peritoneal dialysis as an alternative renal replacement therapy for patients with end-stage renal failure has been developing rapidly worldwide, particularly in China. ${ }^{32}$ However, patients undergoing CAPD show a progressive loss of the monolayer of mesothelial cells because of the development of EMT and peritoneal fibrosis. Emerging evidence shows that TGF- $\beta$ is a key mediator of EMT and peritoneal fibrosis. However, downstream mechanisms of TGF- $\beta$-mediated peritoneal fibrosis remain largely unclear. In the present study, we performed the microRNA microarray analysis in a rat model of PD. Results showed that several miRNAs, such as miR-205, miR-664, miR-29b, and miR-30a, were significantly changed, along with the development of peritoneal fibrosis. Because Snail is a target gene of miR-30a during EMT, we studied the interaction between miR-30a and Snail in the process of EMT and peritoneal fibrosis in vivo and in vitro. We found that miR30a was down-regulated in both the PD rat model and CAPD patients with peritoneal fibrosis. In vitro, TGF$\beta 1$-induced EMT was also associated with down-regulation of miR-30a but up-regulation of Snail, suggesting a close link between miR-30a and Snail during EMT.

The most significant finding in our study was that miR$30 \mathrm{a}$ acted as a negative regulator of TGF- $\beta 1$-induced Snai1-dependent EMT during peritoneal fibrosis. It is well documented that Snail is an important transcript factor of EMT by inhibiting an E-box gene, such as E-cad. ${ }^{33-35}$ The Snail family of transcription factors, which include Snai1, Snai2 (Slug), and Snai3, contain a characteristic C-terminal domain with four to six zinc finger proteins that mediate sequence-specific DNA binding to E-box elements. ${ }^{33-35} \mathrm{~A}$ recent study showed that miR-30a is a tumor suppressor and negatively regulates Beclin-1-dependent autophagic activity. ${ }^{36}$ In the present study, we added new information that miR-30a negatively regulated Snail protein but not mRNA expression, indicating that miR-30a repressed the translation of Snai1, rather than promoted degradation of Snai1 mRNA. Indeed, miR-30a was able to regulate Snai1 expression by binding to the $3^{\prime}$ UTR of the Snail, as evidenced by the fact that overexpression of miR-30a was capable of inhibiting the luciferase activity of wild-type Snail, but mutation of the binding site of miR-30a on Snail blocked the inhibitory effect of miR-30a on the $3^{\prime}$ UTR reporter activity of Snai1. This observation was consistent with the finding that Snail is post-transcriptionally targeted by the miR-30a in non-small cell lung cancer. ${ }^{29}$

We found that TGF- $\beta 1$ induced a loss of miR-30a to mediate EMT and peritoneal fibrosis. This was consistent with the well-known role of TGF- $\beta 1$ in EMT and peritoneal fibrosis. ${ }^{37,38}$ The ability of miR-30a to block TGF- $\beta 1-$ induced EMT and fibrosis revealed the functional importance of miR-30a in negatively regulating the process of peritoneal fibrosis. Moreover, overexpression of miR-30a was able to block the migration activity of mesothelial cells induced by TGF- $\beta 1$. This finding suggested that miR-30a negatively regulates TGF- $\beta 1$-induced EMT and functions to inhibit the EMT cell migration activity. This observation may well explain the finding that down-regulation of the miR-30 family members is found in human metastatic cancers. ${ }^{39-42}$

More important, the present study also provided evidence that overexpression of miR-30a was capable of inhibiting EMT and peritoneal fibrosis in vivo. These results suggested that miR-30a may be an effective therapeutic agent for 
peritoneal fibrosis. In conclusion, the present study identified that miR-30a was down-regulated in the fibrotic peritoneal tissues of both the PD rat model and CAPD patients. miR-30a functioned to negatively regulate TGF- $\beta 1$-induced EMT and peritoneal fibrosis by targeting Snail both in vitro and in vivo. Overexpression of miR-30a may represent an effective therapeutic potential for peritoneal fibrosis.

\section{Acknowledgment}

We thank Prof. Haiping Mao for her suggestions during the design of this work.

\section{Supplemental Data}

Supplemental material for this article can be found at http://dx.doi.org/10.1016/j.ajpath.2013.05.019.

\section{References}

1. Yanez-Mo M, Lara-Pezzi E, Selgas R, Ramirez-Huesca M, Dominguez-Jimenez C, Jimenez-Heffernan JA, Aguilera A, SanchezTomero JA, Bajo MA, Alvarez V, Castro MA, del Peso G, Cirujeda A, Gamallo C, Sanchez-Madrid F, Lopez-Cabrera M: Peritoneal dialysis and epithelial-to-mesenchymal transition of mesothelial cells. N Engl J Med 2003, 348:403-413

2. Honda K, Hamada C, Nakayama M, Miyazaki M, Sherif AM, Harada T, Hirano H: Impact of uremia, diabetes, and peritoneal dialysis itself on the pathogenesis of peritoneal sclerosis: a quantitative study of peritoneal membrane morphology. Clin J Am Soc Nephrol 2008, 3:720-728

3. Williams JD, Craig KJ, Topley N, Von Ruhland C, Fallon M, Newman GR, Mackenzie RK, Williams GT: Morphologic changes in the peritoneal membrane of patients with renal disease. J Am Soc Nephrol 2002, 13:470-479

4. Kim YL: Update on mechanisms of ultrafiltration failure. Perit Dial Int 2009, 29(Suppl 2):S123-S127

5. Borok Z: Role for alpha3 integrin in EMT and pulmonary fibrosis. J Clin Invest 2009, 119:7-10

6. Zeisberg M, Hanai J, Sugimoto H, Mammoto T, Charytan D, Strutz F, Kalluri R: BMP-7 counteracts TGF-beta1-induced epithelial-tomesenchymal transition and reverses chronic renal injury. Nat Med 2003, 9:964-968

7. Bartel DP: MicroRNAs: genomics, biogenesis, mechanism, and function. Cell 2004, 116:281-297

8. Calin GA, Croce CM: MicroRNA signatures in human cancers. Nat Rev 2006, 6:857-866

9. Meister G, Tuschl T: Mechanisms of gene silencing by doublestranded RNA. Nature 2004, 431:343-349

10. Ambros V: The functions of animal microRNAs. Nature 2004, 431: 350-355

11. Krützfeldt J, Stoffel M: MicroRNAs: a new class of regulatory genes affecting metabolism. Cell Metab 2006, 4:9-12

12. Gregory PA, Bert AG, Paterson EL, Barry SC, Tsykin A, Farshid G, Vadas MA, Khew-Goodall Y, Goodall GJ: The miR-200 family and miR-205 regulate epithelial to mesenchymal transition by targeting ZEB1 and SIP1. Nat Cell Biol 2008, 10:593-601

13. Kong W, Yang H, He L, Zhao JJ, Coppola D, Dalton WS, Cheng JQ: MicroRNA-155 is regulated by the transforming growth factor beta/Smad pathway and contributes to epithelial cell plasticity by targeting RhoA. Mol Cell Biol 2008, 28:6773-6784

14. Jiang X, Tsitsiou E, Herrick SE, Lindsay MA: MicroRNAs and the regulation of fibrosis. FEBS J 2010, 277:2015-2021
15. Zhang K, Zhang H, Zhou X, Tang WB, Xiao L, Liu YH, Liu H, Peng YM, Sun L, Liu FY: miRNA589 regulates epithelialmesenchymal transition in human peritoneal mesothelial cells. J Biomed Biotechnol 2012, 2012:673096

16. Sefton M, Sánchez S, Nieto MA: Conserved and divergent roles for members of the Snail family of transcription factors in the chick and mouse embryo. Development 1998, 125:3111-3121

17. Batlle E, Sancho E, Franci C, Dominguez D, Monfar M, Baulida J, Garcia De Herreros A: The transcription factor snail is a repressor of E-cadherin gene expression in epithelial tumour cells. Nat Cell Biol 2000, 2:84-89

18. Nie J, Dou X, Hao W, Wang X, Peng W, Jia Z, Chen W, Li X, Luo N, Lan HY, Yu XQ: Smad7 gene transfer inhibits peritoneal fibrosis. Kidney Int 2007, 72:1336-1344

19. Rougier JP, Moullier P, Piedagnel R, Ronco PM: Hyperosmolality suppresses but TGF beta 1 increases MMP9 in human peritoneal mesothelial cells. Kidney Int 1997, 51:337-347

20. Rougier JP, Guia S, Hagege J, Nguyen G, Ronco PM: PAI-1 secretion and matrix deposition in human peritoneal mesothelial cell cultures: transcriptional regulation by TGF-beta 1. Kidney Int 1998 , 54:87-98

21. Margetts PJ, Kolb M, Galt T, Hoff CM, Shockley TR, Gauldie J: Gene transfer of transforming growth factor-betal to the rat peritoneum: effects on membrane function. J Am Soc Nephrol 2001, 12: 2029-2039

22. Chung AC, Huang XR, Meng X, Lan HY: miR-192 mediates TGFbeta/Smad3-driven renal fibrosis. J Am Soc Nephrol 2010, 21: $1317-1325$

23. Qin W, Chung AC, Huang XR, Meng XM, Hui DS, Yu CM, Sung JJ, Lan HY: TGF-beta/Smad3 signaling promotes renal fibrosis by inhibiting miR-29. J Am Soc Nephrol 2011, 22:1462-1474

24. Zhong X, Chung AC, Chen HY, Meng XM, Lan HY: Smad3-mediated upregulation of miR-21 promotes renal fibrosis. J Am Soc Nephrol 2011, 22:1668-1681

25. Cheng CW, Wang HW, Chang CW, Chu HW, Chen CY, Yu JC, Chao JI, Liu HF, Ding SL, Shen CY: MicroRNA-30a inhibits cell migration and invasion by downregulating vimentin expression and is a potential prognostic marker in breast cancer. Breast Cancer Res Treat 2012, 134:1081-1093

26. Du B, Ma LM, Huang MB, Zhou H, Huang HL, Shao P, Chen YQ, Qu LH: High glucose down-regulates miR-29a to increase collagen IV production in HK-2 cells. FEBS Lett 2010, 584:811-816

27. Livak KJ, Schmittgen TD: Analysis of relative gene expression data using real-time quantitative PCR and the $2^{-\Delta \Delta C T}$ Method. Methods 2001, 25:402-408

28. Brock R, Hamelers IH, Jovin TM: Comparison of fixation protocols for adherent cultured cells applied to a GFP fusion protein of the epidermal growth factor receptor. Cytometry 1999, 35:353-362

29. Kumarswamy R, Mudduluru G, Ceppi P, Muppala S, Kozlowski M, Niklinski J, Papotti M, Allgayer H: MicroRNA-30a inhibits epithelialto-mesenchymal transition by targeting Snail and is downregulated in non-small cell lung cancer. Int J Cancer 2012, 130:2044-2053

30. Aubertin G, Choquet P, Dheu C, Constantinesco A, Ratomponirina C, Zaloszyc A, Passlick-Deetjen J, Fischbach M: The impact of dialysis solution biocompatibility on ultrafiltration and on free water transport in rats. Pediatr Nephrol 2011, 27:131-138

31. Pajek J, Kveder R, Bren A, Gucek A, Bucar M, Skoberne A, Waniewski J, Lindholm B: Short-term effects of bicarbonate/lactatebuffered and conventional lactate-buffered dialysis solutions on peritoneal ultrafiltration: a comparative crossover study. Nephrol Dial Transplant 2009, 24:1617-1625

32. Jiang Z, Yu X: Advancing the use and quality of peritoneal dialysis by developing a peritoneal dialysis satellite center program. Perit Dial Int 2011, 31:121-126

33. Barrallo-Gimeno A, Nieto MA: The Snail genes as inducers of cell movement and survival: implications in development and cancer. Development 2005, 132:3151-3161 
34. Cho HJ, Baek KE, Saika S, Jeong MJ, Yoo J: Snail is required for transforming growth factor-beta-induced epithelial-mesenchymal transition by activating PI3 kinase/Akt signal pathway. Biochem Biophys Res Commun 2007, 353:337-343

35. Vesuna F, van Diest P, Chen JH, Raman V: Twist is a transcriptional repressor of E-cadherin gene expression in breast cancer. Biochem Biophys Res Commun 2008, 367:235-241

36. Zhu H, Wu H, Liu X, Li B, Chen Y, Ren X, Liu CG, Yang JM: Regulation of autophagy by a beclin 1-targeted microRNA, miR-30a, in cancer cells. Autophagy 2009, 5:816-823

37. Wahab NA, Mason RM: A critical look at growth factors and epithelial-to-mesenchymal transition in the adult kidney: interrelationships between growth factors that regulate EMT in the adult kidney. Nephron 2006, 104:e129-e134

38. Weiskirchen R, Meurer SK, Gressner OA, Herrmann J, BorkhamKamphorst E, Gressner AM: BMP-7 as antagonist of organ fibrosis. Front Biosci 2009, 14:4992-5012
39. Baffa R, Fassan M, Volinia S, O’Hara B, Liu CG, Palazzo JP, Gardiman M, Rugge M, Gomella LG, Croce CM, Rosenberg A: MicroRNA expression profiling of human metastatic cancers identifies cancer gene targets. J Pathol 2009, 219:214-221

40. Budhu A, Jia HL, Forgues M, Liu CG, Goldstein D, Lam A, Zanetti KA, Ye QH, Qin LX, Croce CM, Tang ZY, Wang XW: Identification of metastasis-related microRNAs in hepatocellular carcinoma. Hepatology 2008, 47:897-907

41. Heinzelmann J, Henning B, Sanjmyatav J, Posorski N, Steiner T, Wunderlich H, Gajda MR, Junker K: Specific miRNA signatures are associated with metastasis and poor prognosis in clear cell renal cell carcinoma. World J Urol 2011, 29:367-373

42. Yanaihara N, Caplen N, Bowman E, Seike M, Kumamoto K, Yi M, Stephens RM, Okamoto A, Yokota J, Tanaka T, Calin GA, Liu CG, Croce CM, Harris CC: Unique microRNA molecular profiles in lung cancer diagnosis and prognosis. Cancer Cell 2006 9:189-198 